УДК 577.2

DOI: $10.33184 /$ spbgb-2021-09-21.50

\title{
Полигенный анализ генетических маркеров долголетия с использованием программы APSampler
}

\author{
( В.В. Эрдман ${ }^{1 *}$, И.А. Туктарова ${ }^{1}$, К.В. Данилко ${ }^{2}$, Я.Р. Тимашева ${ }^{1,2}$, Т.В. Викторова ${ }^{2}$, \\ T.P. Насибуллин ${ }^{1}$ \\ ${ }^{1}$ Институт биохимии и генетики Уфимского фредерального исследовательского \\ центра РАH \\ Россия, Республика Башкортостан, 450054 г. Уфра, проспект Октября, 71. \\ ${ }^{2}$ Башкирский государственный медицинский университет \\ Россия, Республика Башкортостан, 450008 г. Уфра, ул. Ленина 3. \\ *Email: danivera@mail.ru
}

Установлены мультилокусные маркеры долголетия в этнической группе русских, жителей Республики Башкортостан, по ряду генов, участвующих в адаптации. Ключевые гены выявленных полигенных кластеров кодируют ферменты, участвующие в метаболизме активных фоорм кислорода первого и второго этапов, а также токсичных соединений эндогенной и экзогенной природы.

Ключевые слова: долголетие, генетический полиморфизм, мультилокусный анализ, APSampler, адаптация, гены ферментов метаболизма свободных радикалов и токсичных соединений

Долголетие - сложный феномен человеческой жизни, характеризующийся увеличением продолжительности жизни с сохранением физических и когнитивных способностей. Долгожителями считаются люди, достигшие возраста, существенно превышающего средний показатель продолжительности жизни. Представители данной группы населения мира устойчивы к распространенным социально значимым возрастассоциированным заболеваниям. Однако примечательно и то, что в условиях носительства одного или нескольких широко распространенных патологий долгожители обладают повышенной выживаемостью [1], что может свидетельствовать о наличии определенных адаптационных эндогенных механизмов.

Среди значимых для успешной адаптации организма молекулярно-генетических фракторов особая роль отводится генам антиоксидантной системы и метаболизма токсичных соединений. Молекулы кислорода и его активные формы, постоянно образующиеся в клетках, являются индукторами большого количества метаболических процессов, протекающих в физиологических и патологических условиях жизнедеятельности организма [2]. Система метаболизма токсичных соединений, с появлением техногенных агентов взявшая на себя роль борьбы с ксенобиотиками, эволюционно приспособлена к элиминации из организма побочных продуктов обмена веществ. Таким образом, в рамках адаптационной гипотезы многофакторный характер френомена долгожительства определяется сложной комбинацией генов системы эндо- и экзогенного метаболизма.

Для анализа характера взаимодействия компонентов генной сети применяется целый ряд биоинформатических и статистических инструментов [3, 4]. Одной из программ, приспособленных для обработки полигенных данных, является APSampler, paнеe раз- 
работанная для поиска составных генетических биомаркеров методом Монте-Карло Марковскими цепями (МСMC) [5]. Данная программа включает набор функций, необходимый для поиска мультилокусных маркеров предрасположенности, в том числе, таких, как оценка ассоциаций для найденных сочетаний с помощью точного критерия Фишера, возможность проведения анализа ассоциации для комбинации конкретных принудительно выбираемых аллелей или генотипов. Это дает ей преимущество перед рядом схожих программ (BEAM, PLINK, MDR, LogicReg), предназначенных для полигенного анализа ассоциаций [6].

Цель работы заключалась в поиске мультилокусных маркеров долголетия в генах фрерментов метаболизма свободных радикалов и токсичных соединений с использованием программы APSampler у этнических русских, проживающих в Республике Башкортостан.

Материалы и методы. Исследование выполнено в соответствии с этическими принципами проведения медико-биологических исследований с участием человека в качестве субъекта, закрепленными в Хельсинской декларации Всемирной медицинской ассоциации [World Medical Association, 2013], и одобрено комитетом по биоэтике ИБГ УФИЦ РАН. Все обследуемые лица дали письменное информированное согласие на участие в исследовании. Выборка была сформирована из лиц, фризически сохранных по сердечно-сосудистой и нервной системе. В отношении людей старшей возрастной когорты (лиц пожилого, старческого возраста и долгожителей), у которых возрастное изменение фрункций органов сердечно-сосудистой системы является, за редким исключением, практически нормой, допускалось наличие в анамнезе атеросклероза, кардиосклероза и церебросклероза. Для долгожителей разработана специальная позиция так называемая «успешность», проявляющаяся в способности самообслуживания, физической активности, сохранности сознания.

Была сформирована выборка лиц, принадлежащих к этнической группе русских, проживающих на территории Республики Башкортостан, включающая 490 человек в возрасте от 1 до 102 лет. Общая выборка была дифференцирована на возрастные группы, выделенные на основе антропометрических, фризиологических и биохимических особенностей онтогенеза [7].

В качестве материала для исследования использовали образцы ДНК, выделенные из 8 мл периферической венозной крови методом фенольно-хлороформной экстракции.

Для исследования были выбраны 20 полиморфных маркеров генов антиоксидантной защиты, метаболизма глутатиона, метаболизма ксенобиотиков и факторов транскрипции, обеспечивающих редокс-гомеостаз: rs2070424*SOD1, rs4880*SOD2, rs662*PON1, rs $1050450^{\star} G P X 1, \quad$ rs $1695^{\star} G S T P 1, \quad r s 1131341^{*} N Q O 1, \quad r s 20417^{\star} P T G S 2, \quad r s 1208^{*} N A T 2$, rs 1801133*MTHFR, rs 1045642*ABCB, rs762551*CYP1A2, rs4244285*CYP2C19, rs3803304* $A K T 1$, rs $11549465^{\star} H I F 1 A$, rs $7493^{*} P O N 2$, rs $10098474^{*} M S R A$, rs $1001179^{*} C A T$, rs $1799895^{\star} S O D 3$, rs $1002149^{*} G S R$ и rs6721961*NFE2L2. Аллельные варианты изучаемых полиморфных сайтов определяли методом полимеразной цепной реакции (ПЦР) с последующей обработкой ампликонов эндонуклеазой рестрикции, с использованием аллель-специфичных праймеров или методом ПЦР с детекцией результатов в режиме реального времени. Условия проведения эксперимента, олигонуклеотидные последовательности для идентификации полиморфных локусов генов были подобраны с помощью приложения PrimerSelect 5.05 из пакета программы DNAStar Inc и базы данных NCBI (https://www.ncbi.nlm.nih.gov/).

Соответствие наблюдаемых частот генотипов в группе лиц среднего возраста теоретически ожидаемому равновесному распределению Харди-Вайнберга тестировали в программе Arlequn (V. 3.0). Мультилокусные генетические маркеры долголетия опре- 
деляли с использованием метода Монте-Карло Марковскими цепями (МСМС) в программе APSampler (V.3.6.1); в качестве поправки на множественность сравнений $\left(\mathrm{P}_{\text {cor }}\right)$ использовался пермутационный тест (WinPepi V.11.39).

Результаты и обсуждение. В этнической группе русских установлено 11 мультилокусных маркеров, предрасполагающих к долголетию (OR>1), и 6 мультилокусных маркеров, носительство которых снижает шансы достижения долголетия $(\mathrm{OR}<1)$ (Табл. 1). Основными компонентами сочетаний, ассоциированных с долголетием, являются аллели $C A T^{\star} T, G P X 1^{*} T$ и $M S R A^{*} T$, причем аллель $M S R A^{\star} T$ встречается в гомозиготном состоянии в сочетании с наиболее выраженными статистическими показателями $\left(\mathrm{OR}=5.641, \mathrm{P}=0.0004, \mathrm{P}_{\text {cor }}=0.002\right)$. Также часто встречающими элементами этих сочетаний являются аллель $S O D 2^{\star} C$ и генотип $S O D 1^{\star} A / A$. Вероятность стать долгожителем снижается у носителей составных генетических маркеров $P O N 2{ }^{*} C+C A T^{*} C+N Q O 1^{*} C+G S R^{*} G \quad\left(\mathrm{OR}=0.278, \quad \mathrm{P}=0.004, \quad \mathrm{P}_{\text {cor }}=0.014\right)$, $H I F 1 A^{*} C+M S R A^{\star} T+S O D 1^{*} G \quad\left(O R=0.201, \quad P=0.011, \quad P_{\text {cor }}=0.04\right), \quad C A T^{*} C+N Q O 1^{*} C+G S R^{\star} G$ $\left(\mathrm{OR}=0.282, \mathrm{P}=0.011, \mathrm{P}_{\text {cor }}=0.041\right)$. Аллель $M S R A^{\star} T$, встречающийся также в предрасполагающих к долголетию сочетаниях с генотипом $S O D 1^{*} A / A$, в комбинации с аллелем $S O D 1^{*} G$ обладает противоположным эфффектом (OR=0.204, $\left.\mathrm{P}=0.012, \mathrm{P}_{\text {cor }}=0.041\right)$.

Выявленные таким образом мультилокусные паттерны долголетия включают гены ферментов, участвующих в метаболизме активных фрорм кислорода первого и второго этапов, а также токсичных соединений эндогенной и экзогенной природы. Так, подавляющее число исследований роли ферментов супероксиддисмутаз (SOD) в патогенезе различных заболеваний и старческих процессов свидетельствует о снижении супероксидазной активности при сопровождающихся развитием окислительного стресса патологиях [8]. Среди этнических русских, достигших долголетия, наблюдается повышение частоты протективного в отношении ряда возраст-зависимых заболеваний генотипа $S O D 1^{*} A / A$. Миссенс-мутация в гене SOD2 (116T>C, rs4880) обусловливает изменение вторичной структуры сигнального пептида и тем самым дестабилизирует его альфаспиральный участок, что влияет на скорость переноса фермента из цитоплазмы в митохондрии и может приводить к абсолютному или относительному локальному дефициту фермента [9]. Показано, что активность SOD2 существенно выше у носителей аллеля $S O D 2^{\star} C$. По нашим данным, аллель $S O D 2^{\star} C$, реализующий вариант фермента с высокой эффективностью в отношении защиты клетки от активных форм кислорода, ассоциирован с долголетием. Метионинсульфоксидредуктаза A (MSRA) относится к семейству ферментов, разрушающих активные формы кислорода. Восстанавливая белки с окисленным метионином, фермент играет большую роль в репарации белков при старении и при воздействии на организм агрессивных экологических фракторов. Высказано предположение, что фрермент MSRA играет важную роль в процессах старения [10]. В нашем исследовании установлена выраженная ассоциация с долголетием аллеля $M S R A^{*} T$. Также в данном исследовании получены интересные результаты по функциональному ДНК-маркеру rs1001179 гена каталазы (CAT). Аллель $C A T^{\star} T$ acсоциирован с низким уровнем активности фрермента в эритроцитах [11], что увеличивает риск развития оксидативного стресса. Действительно, среди пожилого контингента наблюдается рост частоты аллеля $C A T^{\star} C$, ассоциированного с нормальной активностью каталазы, однако к старческому возрасту и у долгожителей вектор изменения частот меняется. Таким образом, аллель САT ность генов глутатионового обмена в процессы, связанные с выживаемостью, адаптацией и долголетием, объясняется их широким функциональным спектром. Помимо антиоксидантой функции, они участвуют в метаболизме ксенобиотиков, активируя их биотрансформацию. Аллель rs $1050450^{\star} T$ гена GPX1 отвечает за более низкую фрерментативную активность продукта и выступает рисковым в отношении развития ряда возраст-ассоциированных заболеваний [12]. В нашем исследовании наблюдается снижение вероятности обнаружения генотипа, гомозиготного по аллелю $G P X 1^{\star} T$, среди долгожителей русской этнической принадлежности. 
Таким образом, мы определили мультилокусные маркеры долголетия у русских, жителей Республики Башкортостан. Выявлены вероятные генные сети, участвующие в формировании стабильного высокоадаптивного фенотипа, позволяющего избежать возрастных патологий или минимизировать их негативное влияние.

Работа выполнена при финансовой поддержке РФФИ и АНА (Грант № 19-54-40007) и мегагрантом Правительства Российской Федерации (№ 075-15-2021-595).

\section{Литература}

1. Maier H., Jeune B., Vaupel J. W. Exceptional lifespans // Springer Nature. 2021. C. 344.

2. Новиков В. Е., Левченкова О. С., Пожилова Е. В. Роль активных форм кислорода в физиологии и патологии клетки и их фармакологическая регуляция // Обзоры по клинической фрармакологии и лекарственной терапии. 2014. Т. 12. №. 4.

3. Пономаренко И.В. Использование метода Multifactor Dimensionality Reduction (MDR) и его модификаций для анализа ген-генных и генно-средовых взаимодействий при генетико-эпидемиологических исследованиях (обзор) // Научные результаты биомедицинских исследований. 2019. T. 5. №. 1. DOI: 10.18413/2313-8955-2019-5-1-0-1

4. Полоников А. В., Клесова Е. Ю., Азарова Ю. Э. Биоинформатические инструменты и интернет-ресурсы для оценки регуляторного потенциала полиморфных локусов, установленных полногеномными ассоциативными исследованиями мультифакториальных заболеваний (обзор) // Научные результаты биомедицинских исследований. 2021. T. 7. № 1. C. 15-31. DOI: 10.18413/2658-6533-2020-7-1-0-2.

5. Favorov A. V., Andreewski T. V., Sudomoina M. A. et al. A Markov chain Monte Carlo technique for identification of combinations of allelic variants underlying complex diseases in humans // Genetics. 2005. V. 171. №. 4. P. 2113-2121. DOI: 10.1534/genetics. 105.048090

6. Lvovs D., Favorova O. O., Favorov A. V. A polygenic approach to the study of polygenic diseases // Acta Naturae (англоязычная версия). 2012. V. 4. №. 3 (14). P. 59-71.

7. Хрисанфова Е.Н. Основы геронтологии (Антропологические аспекты). М.: Владос, 1999. - 151 с.

8. Lewandowski Ł., Kepinska M., Milnerowicz H. The copper-zinc superoxide dismutase activity in selected diseases // European journal of clinical investigation. 2019. V. 49. №. 1. P. e13036. DOI: $10.1111 /$ eci.13036

9. Колесникова Л., Баирова Т. А., Первушина О. А. Гены ферментов антиоксидантной системы // Вестник Российской академии медицинских наук. 2013. Т. 68. №. 12.

10. Oien D.B., Moskovitz J. Genetic regulation of longevity and age-associated diseases through the methionine sulfoxide reductase system // Biochimica et Biophysica Acta (BBA)Molecular Basis of Disease. 2018. https://doi.org/10.1016/j.bbadis.2018.11.016

11. Forsberg L., Lyrenas U., De Faire R., Mortgenstern A. A common functional C-T substitution in the promoter region of the human catalase gene influences transcription factor binding, reporter gene transcription and is correlated to blood catalase levels // Free Radical Biol Med 2001. V. 30. P. 500-505. https://doi.org/10.1016/S0891-5849(00)00487-1 
12. Ravn-Haren G., Olsen A., Tjønneland A. et al. Associations between GPX1 Pro198Leu polymorphism, erythrocyte GPX activity, alcohol consumption and breast cancer risk in a prospective cohort study // Carcinogenesis. 2006. T. 27. №. 4. C. 820-825.

Таблица 1. Сочетания аллелей/генотипов, ассоциированные с возрастом в этнической группе русских, полученные с помощью алгоритма APSampler

\begin{tabular}{|c|c|c|c|c|c|c|c|}
\hline \multirow{2}{*}{ № } & \multirow{2}{*}{ Сочетание } & Долгожители & Средний возраст & \multirow{2}{*}{ OR } & \multirow{2}{*}{$95 \% \mathrm{Cl}$} & \multirow{2}{*}{$P$} & \multirow{2}{*}{$P_{\text {cor }}$} \\
\hline & & \multicolumn{2}{|c|}{$p, \%$} & & & & \\
\hline 1 & $\mathrm{CAT}^{*} \mathrm{~T}+\mathrm{MSRA}{ }^{*} \mathrm{~T} / \mathrm{T}+\mathrm{GPXI}{ }^{*} \mathrm{~T}$ & 29.730 & 6.977 & 5.641 & $\begin{array}{l}2.254- \\
14.114\end{array}$ & $4 \times 10^{-4}$ & 0.002 \\
\hline 2 & $\mathrm{HIF} 1 \mathrm{~A}^{*} \mathrm{C}+\mathrm{MSRA}{ }^{*} \mathrm{~T}+\mathrm{SOD} 1{ }^{*} \mathrm{~A} / \mathrm{A}$ & 92.105 & 69.189 & 5.195 & $\begin{array}{l}1.534- \\
17.592\end{array}$ & 0.002 & 0.006 \\
\hline 3 & $\mathrm{CAT}^{\star} \mathrm{T}+\mathrm{MSRA}{ }^{\star} T+G P X I^{\star} T+G S T P 1^{*} A$ & 37.838 & 14.535 & 3.579 & $\begin{array}{l}1.627- \\
7.872\end{array}$ & 0.002 & 0.006 \\
\hline 4 & $\mathrm{CAT}^{*} \mathrm{~T}+\mathrm{MSRA}{ }^{*} \mathrm{~T}+\mathrm{GPXI}{ }^{*} \mathrm{~T}+\mathrm{SOD} 2^{*} \mathrm{C}$ & 32.432 & 11.243 & 3.789 & $\begin{array}{l}1.640- \\
8.757\end{array}$ & 0.002 & 0.007 \\
\hline 5 & $\mathrm{CAT}^{*} \mathrm{~T}+\mathrm{GPXI}{ }^{*} \mathrm{~T} / \mathrm{C}+\mathrm{GSTP} 1^{*} \mathrm{~A}$ & 36.842 & 15.166 & 3.263 & $\begin{array}{l}1.528- \\
6.970\end{array}$ & 0.003 & 0.011 \\
\hline 6 & $\mathrm{MSRA}^{*} \mathrm{~T}+\mathrm{SOD} 1^{*} \mathrm{~A} / \mathrm{A}$ & 92.105 & 70.588 & 4.861 & $\begin{array}{l}1.435- \\
16.471 \\
\end{array}$ & 0.003 & 0.012 \\
\hline 7 & $\mathrm{CAT}^{*} \mathrm{~T}+\mathrm{MSRA}{ }^{*} \mathrm{~T}+\mathrm{GPXI}{ }^{*} \mathrm{~T}$ & 37.838 & 16.279 & 3.130 & $\begin{array}{l}1.438- \\
6.815\end{array}$ & 0.004 & 0.018 \\
\hline 8 & $\mathrm{CAT}^{*} \mathrm{~T}+\mathrm{GPXI}{ }^{*} \mathrm{~T} / \mathrm{C}+\mathrm{SOD} 2^{*} \mathrm{C}$ & 31.579 & 12.500 & 3.231 & $\begin{array}{l}1.455- \\
7.176\end{array}$ & 0.005 & 0.018 \\
\hline 9 & $\mathrm{CAT}^{\star} \mathrm{T}+\mathrm{GPXI}{ }^{\star} \mathrm{T} / \mathrm{C}$ & 36.842 & 16.509 & 2.950 & $\begin{array}{l}1.390- \\
6.259 \\
\end{array}$ & 0.005 & 0.019 \\
\hline 10 & $\mathrm{SOD} 1{ }^{*} \mathrm{~A} / \mathrm{A}+\mathrm{SOD}{ }^{*} \mathrm{~T}$ & 79.070 & 60.251 & 2.492 & $\begin{array}{l}1.144- \\
5.432 \\
\end{array}$ & 0.013 & 0.044 \\
\hline 11 & $\mathrm{MSRA}^{*} \mathrm{~T} / \mathrm{T}+\mathrm{GPXI}{ }^{\star} \mathrm{C}+\mathrm{GSTP} 1^{*} \mathrm{~A}$ & 59.459 & 37.968 & 2.396 & $\begin{array}{l}1.167- \\
4.921 \\
\end{array}$ & 0.013 & 0.046 \\
\hline 12 & $\mathrm{PON} 2{ }^{*} \mathrm{C}+\mathrm{CAT}^{*} \mathrm{C}+\mathrm{NQO} 1^{*} \mathrm{C}+\mathrm{GSR}{ }^{*} \mathrm{G}$ & 60.000 & 84.354 & 0.278 & $\begin{array}{l}0.118- \\
0.654\end{array}$ & 0.004 & 0.014 \\
\hline 13 & $\mathrm{PON} 2{ }^{*} \mathrm{C}+\mathrm{NQO} 1{ }^{*} \mathrm{C}+\mathrm{GSTP} 1{ }^{*} \mathrm{G}$ & 28.125 & 53.503 & 0.340 & $\begin{array}{l}0.148- \\
0.781\end{array}$ & 0.007 & 0.028 \\
\hline 14 & $\mathrm{HIF} \mathrm{A}^{*} \mathrm{C}+\mathrm{MSRA}^{*} \mathrm{~T}+\mathrm{SOD} 1^{*} \mathrm{G}$ & 5.263 & 21.622 & 0.201 & $\begin{array}{c}0.047- \\
0.873 \\
\end{array}$ & 0.011 & 0.040 \\
\hline 15 & $\mathrm{MSRA}^{*} \mathrm{~T}+\mathrm{GSR}{ }^{*} \mathrm{G}+\mathrm{SOD} 1^{*} \mathrm{G}$ & 5.263 & 21.622 & 0.201 & $\begin{array}{l}0.047- \\
0.873 \\
\end{array}$ & 0.011 & 0.040 \\
\hline 16 & $\mathrm{CAT}^{*} \mathrm{C}+\mathrm{NQO} 1{ }^{*} \mathrm{C}+\mathrm{GSR}{ }^{\star} \mathrm{G}$ & 73.333 & 90.686 & 0.282 & $\begin{array}{l}0.111- \\
0.721 \\
\end{array}$ & 0.011 & 0.041 \\
\hline 17 & $\mathrm{MSRA}^{*} \mathrm{~T}+\mathrm{SOD} 1{ }^{*} \mathrm{G}$ & 5.263 & 21.390 & 0.204 & $\begin{array}{l}0.047- \\
0.885 \\
\end{array}$ & 0.012 & 0.041 \\
\hline
\end{tabular}

Примечание. $p$ - частота найденных сочетаний в возрастных группах, OR - показатель соотношения шансов наступления события, $\mathrm{Cl}_{\mathrm{OR}}-95 \%$ доверительный интервал OR, $\mathrm{P}$ - уровень значимости, $\mathrm{P}_{\text {cor }}$ - уровень значимости после введения поправки на множественность сравнений. 


\section{Polygenic analysis of genetic markers of longevity using the APSampler program}

V.V. Erdman ${ }^{1}$, I.A. Tuktarova ${ }^{1}$, K.V. Danilko ${ }^{2}$, Timasheva Y.R. ${ }^{1,2}$, T.V. Viktorova ${ }^{2}$, Nasibullin T.R. ${ }^{1}$

${ }^{1}$ Institute of Biochemistry and Genetics - Subdivision of the Ufa Federal Research Centre of the Russian Academy of Sciences

71 Prospekt Oktyabrya, 450054 Ufa, Republic of Bashkortostan, Russia.

${ }^{2}$ Bashkir State Medical University

3 Lenina Str., 450008 Ufa, Republic of Bashkortostan, Russia.

*Email: danivera@mail.ru

Multilocus markers of longevity have been established in the ethnic group of Russians, residents of the Republic of Bashkortostan, for some genes involved in adaptation. The key genes of the identified polygenic clusters encode enzymes involved in the metabolism of reactive oxygen species of the first and second stages, as well as toxic compounds of endogenous and exogenous nature.

Key words: longevity, genetic polymorphism, multilocus analysis, APSampler, adaptation, genes for enzymes of metabolism of free radicals and toxic compounds 